\title{
Are roadside pedestrian injury patterns predictable in a densely populated, urban setting?
}

Niels D. Martin

Department of Surgery, Thomas Jefferson University

Daniel J. Grabo

Department of Surgery, Thomas Jefferson University

Lili Tang

Department of Surgery, Thomas Jefferson University

Jacqueline Sullivan

Department of Surgery, Thomas Jefferson University

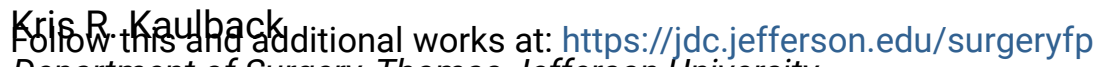
nopartment of Surgery, Thomas Jefferson University

Part of the Surgery Commons

\section{$\frac{\text { Let us know how access to this document benefits you }}{\text { See next page for additional authors }}$}

\section{Recommended Citation}

Martin, Niels D.; Grabo, Daniel J.; Tang, Lili; Sullivan, Jacqueline; Kaulback, Kris R.; Weinstein, Michael S.; Lindenbaum, Gary A.; and Cohen, Murray J., "Are roadside pedestrian injury patterns predictable in a densely populated, urban setting?" (2010). Department of Surgery Faculty

Papers. Paper 33.

https://jdc.jefferson.edu/surgeryfp/33

This Article is brought to you for free and open access by the Jefferson Digital Commons. The Jefferson Digital Commons is a service of Thomas Jefferson University's Center for Teaching and Learning (CTL). The Commons is a showcase for Jefferson books and journals, peer-reviewed scholarly publications, unique historical collections from the University archives, and teaching tools. The Jefferson Digital Commons allows researchers and interested readers anywhere in the world to learn about and keep up to date with Jefferson scholarship. This article has been accepted for inclusion in Department of Surgery Faculty Papers by an authorized administrator of the Jefferson Digital Commons. For more information, please contact: JeffersonDigitalCommons@jefferson.edu. 


\section{Authors}

Niels D. Martin, Daniel J. Grabo, Lili Tang, Jacqueline Sullivan, Kris R. Kaulback, Michael S. Weinstein, Gary A. Lindenbaum, and Murray J. Cohen 


\title{
As submitted to:
}

\section{Journal of Surgical Research}

\author{
And later published as:
}

"Are roadside pedestrian injury patterns predictable in a densely populated, urban setting?"

Volume 163, Issue 2, October 2010, Pages

$$
\text { 323-326 }
$$

DOI: 10.1016/j.jss.2010.03.073 
Title: Are Roadside Pedestrian Injury Patterns Predictable in a Densely Populated, Urban Setting?

Niels D. Martin, MD, Daniel J. Grabo, MD, Lili Tang, MS, Jacqueline Sullivan, PhD, Kris R. Kaulback, MD, Michael S. Weinstein, MD, Gary A. Lindenbaum, MD, Murray J. Cohen, MD

Division of Acute Care Surgery, Department of Surgery, Thomas Jefferson University, Philadelphia, Pennsylvania

Categorization of manuscript: Shock/Sepsis/Trauma/Critical Care

Corresponding Author:

Niels D. Martin, MD

Division of Acute Care Surgery

Thomas Jefferson University

1100 Walnut Street, Suite 702

Philadelphia, PA 19107

(215) 955-2165 office

(215) 923-7957 fax

Niels.Martin@jefferson.edu 


\begin{abstract}
Background: Roadside pedestrian injuries represent a significant portion of trauma team activations, especially at urban trauma centers. Patient demographics and severity of injury vary greatly in this patient population. Herein, we hypothesize that injury patterns may be predictable, especially with respect to age.

Materials \& Methods: All patients with roadside pedestrian injuries evaluated at our urban, level one trauma center from January 2006 through December 2008 were retrospectively reviewed. Data was collected from the institutional trauma registry. Age was used as an independent variable and compared to injury type, substance abuse, discharge setting, and mortality.

Results: There were 226 roadside pedestrian injuries during the study period. Patients were divided into groups according to age, $<20$ years, $21-40,41-65$, and $>65$ years. Head injuries were more prevalent in patients over age sixty-five, $30.4 \%$ vs. $14.0 \%(p=0.05)$. There was a trend for increasing alcohol use in the younger population. The likelihood of discharge to a rehab facility increased with age, $0 \%, 11.8 \%, 38.2 \%, 50.0 \%$ respectively $(\mathrm{p}<0.001)$. Mortality was significantly higher in patients older than 65 years, $15.2 \%$ vs. $3.3 \%(\mathrm{p}=0.049)$.

Conclusions: Roadside pedestrian injuries have predictable injury patterns based on age. Older patients are more likely to have a head injury, longer length of stay, need for a rehab stay, and have a higher mortality. Further studies are needed to correlate precise injuries with collision mechanism and evaluate specific risk factors in this high risk population.
\end{abstract}




\section{Introduction:}

Roadside pedestrian injuries contribute significantly to trauma center activity, especially in urban areas. In 2008 alone, over 69,000 pedestrian injuries occurred in the United States as a result of traffic crashes. ${ }^{1}$ Although its incidence is higher in the pediatric population, adult trauma patients also find this to be a common mechanism of injury. Injuries tend to vary greatly between individual patients, mainly based on the widely variable mechanics of impact, both with the moving vehicle and/or with the ground. Comorbidities also contribute negatively to overall functional recovery, morbidity and mortality. Patient demographics such as age and substance abuse have been linked to survival in previous studies. ${ }^{2-3}$ The purpose of this study is to evaluate multiple patient characteristics such as age and alcohol use, and determine how they relate to injury patterns and ultimate disposition upon hospital discharge.

\section{Methods:}

This study was designed as a contemporary, retrospective evaluation of our prospectively populated institutional trauma registry. This study was conducted with the approval of our Institutional Review Board. Our level one trauma center is located in center-city Philadelphia, a densely populated, urban environment. All patients who presented with the mechanism of Pedestrian struck by motor vehicle during a three year period (January 2006 - December 2008) were reviewed.

Standard demographical data was obtained including age, sex, mechanism of injury, ICU and hospital length of stay. Presence of alcohol use was also documented. Injuries sustained were documented and further described to include anatomic region injured, 
injury severity score, intensive care and overall hospital length of stay. Discharge disposition, morbidities and in-hospital mortality were our main outcome measures.

Data Analysis was performed using SPSS version 14.0. All data were subjected to descriptive statistical analysis yielding frequency scores for categorical data and mean scores for continuous/interval data. Statistically significant differences between variables based on four stratified age groups (under 20 years, $21-40$ years, 41 - 65 years, and 66 years and older) were then determined by conducting inferential statistical analysis using the Chi-Square test for categorical variable comparisons and Analysis of Variance (ANOVA) for continuous/interval data comparisons. Sample size was adequate to protect against occurrence of Type II (false negative) statistical error when conducting both the Chi-Square analysis. A p value less than or equal to 0.05 was considered statistically significant.

\section{Results}

During the study period, our trauma center treated 3718 trauma contacts; $50 \%$ of which were transfers from other institutions for a higher level of care. 226 pedestrian patients were evaluated and treated at our institution after being struck by a motor vehicle. 120 patients were male (53\%). Injury occurrence (Figure 1) was more prevalent in men between the ages of 21 and 65 and in women over age 66. $(\mathrm{p}=0.004)$. Men under age 20 were also more likely to be injured than women of the same age.

Of the 226 overall patients, 115 actually sustained injuries. Of these, 49 (42\%) had injuries to multiple systems including: head, extremities, pelvis, thorax, abdomen, and vertebral column/spinal cord. Of significance, extremity injuries (Figure 2) occurred 
more often in pedestrians who were younger than age 65 as compared to those older than age $65 ; 72.6 \%$ vs. 52.2\% ( $\mathrm{p}=0.031)$ while head injuries (Figure 3) occurred more often in pedestrians with increasing age; $17.9 \%$ vs. $11.5 \%$ vs. $15.1 \%$ vs. $30.4 \%$ for each age group (under 20 years, 21 - 40 years, 41 - 65 years, and 66 years and older), respectively $(\mathrm{p}=0.05)$

212 of the 226 patients required admission to our institution. 100 of these patients required only a single overnight stay, usually for observation, completion of diagnostic testing, or to determine their social disposition. Overall hospital length of stay (Figure 4) was not statistically significantly different across all age groups. However, mean length of stay in the ICU (Figure 5) was significantly higher in injured pedestrians who were 66 years and older as compared to all other age groups $(\mathrm{p}=0.008)(\mathrm{x}=2.11$, sd $=5.039$, range $=0.61-3.60)$

Injury Severity Score (ISS) was statistically higher in the greater than age 65 group, 11.5 vs. 13.4 vs. 11.8 vs. 16.3 for each age group (under 20 years, 21 - 40 years, $41-65$ years, and 66 years and older), respectively $(\mathrm{p}=0.05)$. There were only 13 mortalities in 226 patients. Injured pedestrians between the ages of 21 and 65 were more likely to survive while most deaths (Figure 6) occurred among those who were 66 years and older $(\mathrm{p}=0.049) .5$ of the $7(71 \%)$ patients who died in the $>65$ years old age group were associated with head injuries. There were 4 patients who died in this age group with multiple injured systems.

Injured pedestrians between the ages of 21 and 65 were more likely to be discharged to home. The need for rehabilitation placement (Figure 7) including skilled nursing or subacute rehabilitation increased with age $(\mathrm{p}<0.001)$. 
Of those patients who presented intoxicated by alcohol, $54 \%$ where in age group two (2140 years) whereas only $5.5 \%$ were older than 65 (age group 4$),(\mathrm{p}=0.07)$.

\section{Discussion}

Pedestrians struck by automobiles in urban areas suffer a wide range of injuries accounting for a large number of hospital admissions. Patient demographics such as age and sex play an important role in the anatomic distribution of injuries as well hospital length of stay, disposition, and overall survival..$^{4-5}$ Our findings suggest that patients older than age 65 are at increased risk of injury compared to younger patients. Demetriades et al. found that the anatomic distribution of injuries was related to age. ${ }^{2}$ This suggests that although elderly patients may physiologically be frailer, their ability to react to an impact and protect vital structures such as the head may also be hindered. Overall, head injuries are common in pedestrian roadside injuries. ${ }^{6}$ In our study, head injuries were more prevalent in older patients as compared to younger patients. Younger patients had a higher rate of extremity injuries, potentially because they use their extremities to protect their head and torso.

Beyond the higher incidence of injury, elderly patients in our study also had longer lengths of stay, both in the intensive care unit and during the overall hospitalization. This is certainly related to their higher incidence of injury and need for further care. Kong et al. reported similar findings of increased length of stay. ${ }^{7}$ Similarly, they also found that the elderly pedestrians tended to be female. Further studies on this demographic are needed to explain why females are more commonly struck and injured by motor vehicles. Are elderly women more likely to be active and ambulating on a roadside? Posner et al. 
found that the amount of exposure to traffic was directly related to the risk of being struck in pediatric patients. ${ }^{3}$

Urban roadside injuries are most prevalent in the pediatric population, however their overall incidence of injury is much lower and adults tend to fair worse. ${ }^{6}$ In fact, mortality in our study was highest in the age $>65$ group. Sklar et al. reviewed over a thousand roadside pedestrian injuries and also found that elderly pedestrians struck by motor vehicles die at higher rates because they succumb to their injuries more frequently during their hospitalization than younger patients. ${ }^{8}$ These authors allude to the fact that this may be due to a greater susceptibility of the elderly to metabolic, surgical, and infectious complications after admission to the hospital.

We found a trend for increasing alcohol use in younger patients. Alcohol use has been found to be present in up to $30 \%$ of all pedestrian victims. ${ }^{9}$ Alcohol use is associated with higher injury severity scores and a greater length of stay. ${ }^{9-10}$ Alcohol may also decrease the protective nature of age and head injuries, as the ability of the young to protect their torsos with their extremities, in the event of a collision, may be decreased. This relationship was not demonstrated statistically in our study but should be evaluated in future studies.

Epidemiological studies may allow for further understanding of risk factors involved in roadside pedestrian injuries. ${ }^{7}$ Conditions surrounding the accident such as time of day and weather conditions, may also contribute to injury patterns and outcomes. Urban populations can vary by locale and this may make findings in one study differ from studies performed in other cities. In center-city Philadelphia, there is a large business population by day, theatre and restaurant population in the evening, and a local 
residential population present throughout the day. In some way, this makes our trauma center's population unique. Studies performed in Baltimore and Washington DC reported that pedestrians were usually at fault, but turning vehicles had the highest at fault rate among driver faults. ${ }^{11}$ This type of study may need to be performed for different city "types". Vehicular size and speed also play significant roles. At the slower speed collisions that generally occur in urban areas, sports utility vehicles and trucks account for more significant injuries than cars and carry a higher mortality rate. ${ }^{12-13}$

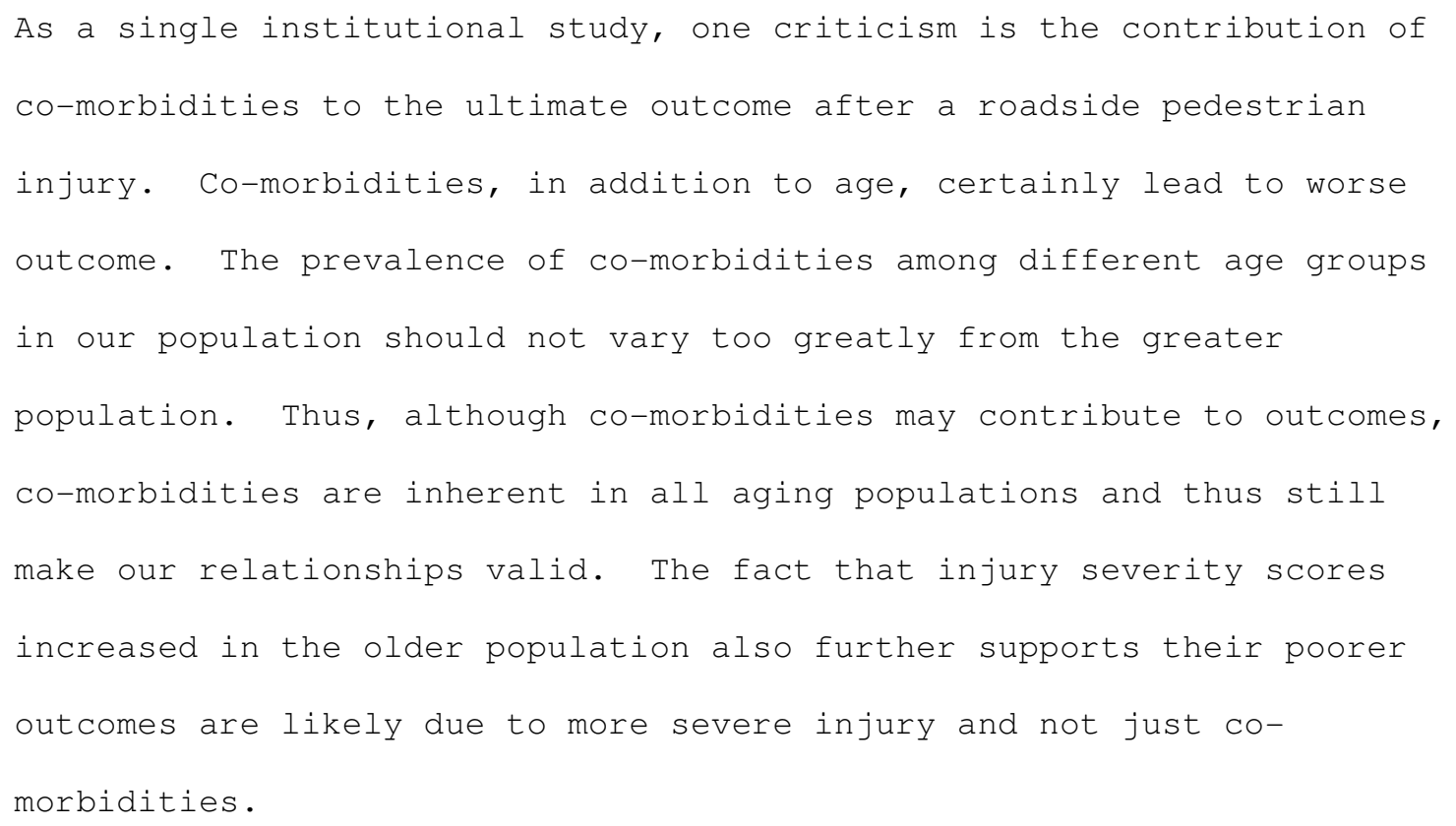

We found an increasing rate of the need for a rehabilitation center stay post hospital discharge as patients got older. These patients certainly have a temporary if not permanent loss of independence that places an additional burden on society. By understanding the factors that contribute to roadside pedestrian injuries in urban areas, we ultimately hope to contrive prevention strategies to help alleviate some of this burden on our healthcare system by a largely preventable problem. Further studies are needed to evaluate pedestrian and driver behaviors that are generally not captured in local registries. 


\section{References:}

1. Pedestrians Traffic Safety Fact Sheet 2008. National Highway Traffic Safety Administration. www.nhtsa.gov. Accessed January $7^{\text {th }}, 2010$

2. D.Demetriades, J.Murray, M.Martin, G.Velmahos, A.Salim, K.Alo, P.Rhee. Pedestrians injured by automobiles: Relationship of age to injury type and severity. J Am Coll Surg. 2004; 199:382-387

3. J.Posner, E.Liao, F.Winston, A.Cnaan, K.Shaw, D.Durbin. Exposure to traffic among urban children injured as pedestrians. Inj Prev. 2002; 8:231-235

4. R.Peng, F.Bongard. Pedestrian versus motor vehicle accidents: an analysis of 5,000 patients. J Am Coll Surg. 1999; 189:343-8

5. M.Vives, S.Kishan, J.Asghar, B.Peng, M.Reiter, S.Milo, D.Livingston. Spinal Injuries in Pedestrians Struck by Motor Vehicles. J Spinal Dis Tech. 2008. 21:281-287

6. R.Derlet, J.Silva, J.Holcroft. Pedestrian accidents: Adult and pediatric injuries. J Emerg Med. 1989; 7:5-8

7. L.Kong, M.Lekawa, R.Navarro. Pedestrian-motor vehicle trauma: An analysis of injury profiles by age. J Am Coll Surg. 1996; 182:17-23.

8. D.Sklar, G.Demarest, P.McFeeley. Increased pedestrian mortality among the elderly. Am J Emerg Med. 1989; 7:387-90

9. D Jehle, E.Cottington. Effect of alcohol consumption on outcome of pedestrian victims. Ann Emerg Med. 1988; 17:953-6

10. A. Bradbury. Pattern and severity of injury sustained by pedestrians in road traffic accidents with particular reference to the effect of alcohol. Injury. 1991; 22:132-4

11. D.Preusser, J.Wells, A.Williams, H.Weinstein. Pedestrian crashes in Washington, DC and Baltimore. Accident Analysis \& Prevention. 2002; 34:703-10

12. M.Ballesteros, P.Dischinger, P. Langenberg. Pedestrian injuries and vehicle type in Maryland, 1995-1999. Accident Analysis \& Prevention. 2004; 36:73-81

13. L.Paulozzi. United States pedestrian fatality rates by vehicle type. Inj Prev. 2005; $11: 232-6$ 


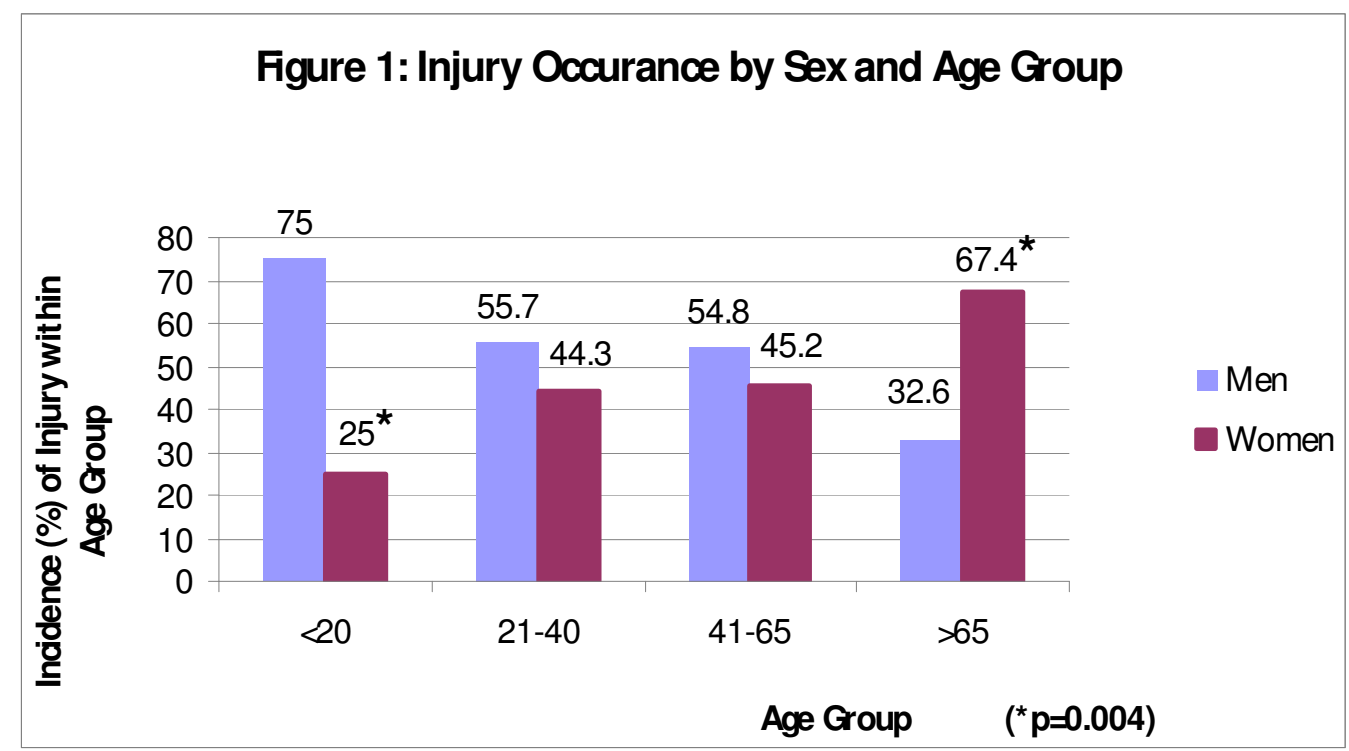

Figure 1: Injury Occurrence by Sex and Age Group. This graph represents the percentage of injured patients within each age group as compared to sex, thus displaying how injury patterns vary by sex within each particular age group. 


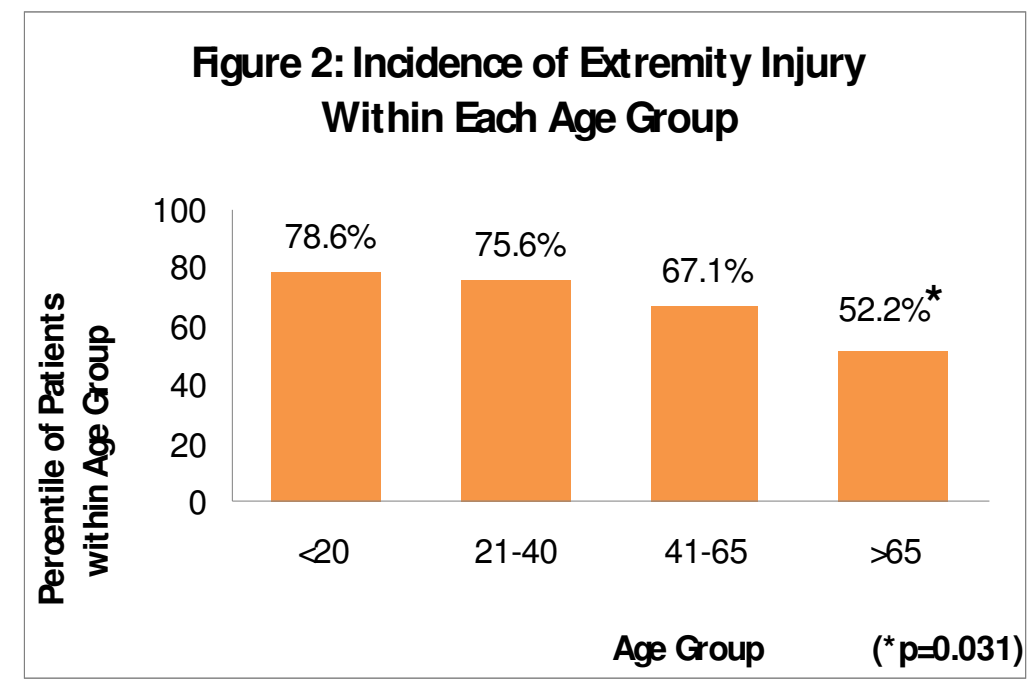

Figure 2: Incidence of Extremity Injury Within Each Age Group. Injuries to extremities occurred less frequently in the greater than 65 age group. 


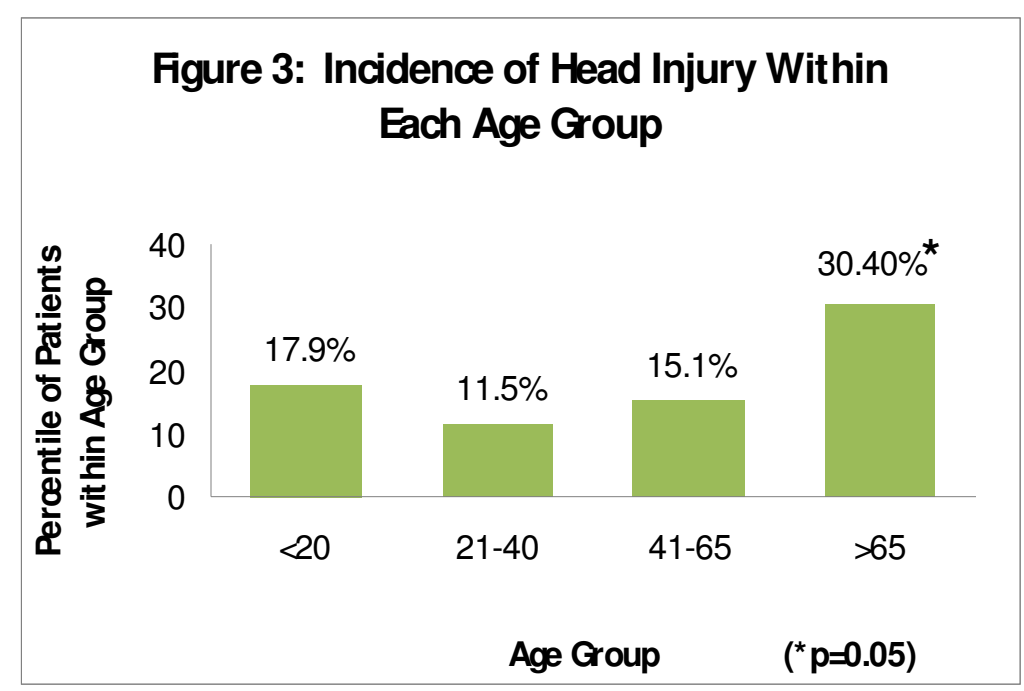

Figure 3: Incidence of Head Injury Within Each Age Group. This figure represents the increasing occurrence of head injury that was observed in patients greater than 65 years old. 


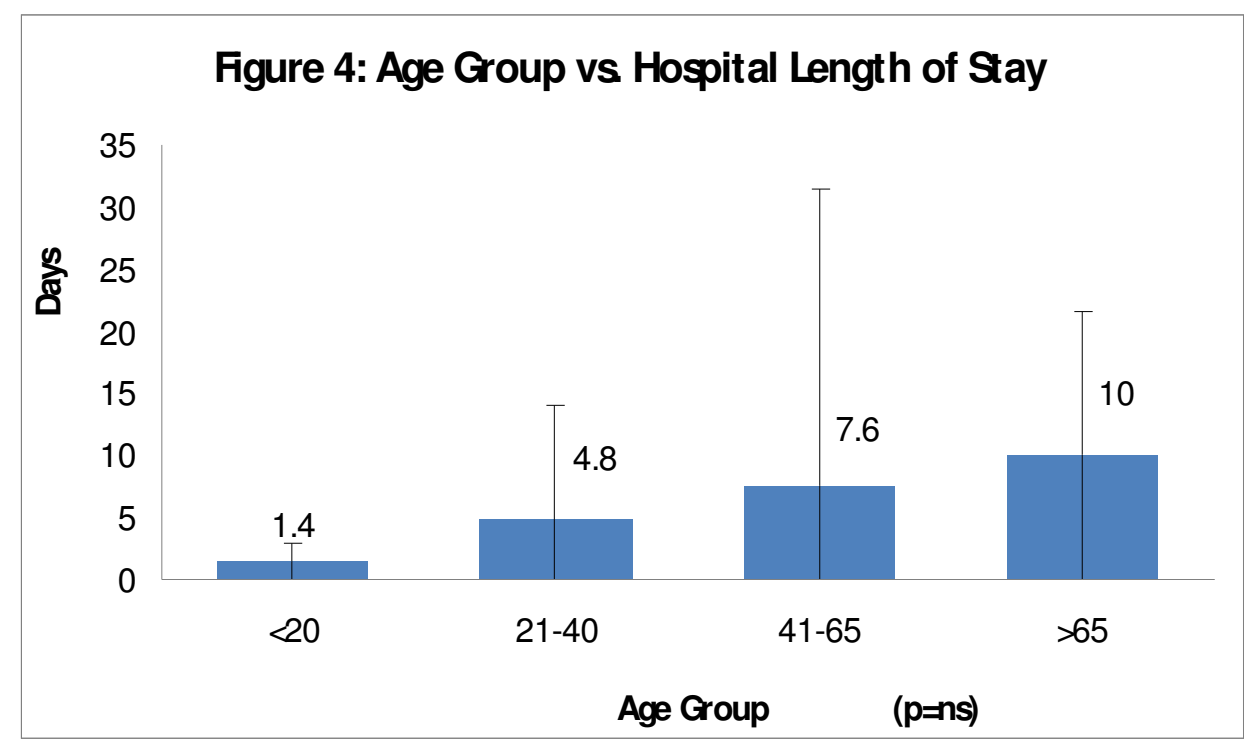

Figure 4: Hospital Length of Stay (LOS). Depicted in this figure is hospital length of stay displaying an increase as age group increases. 


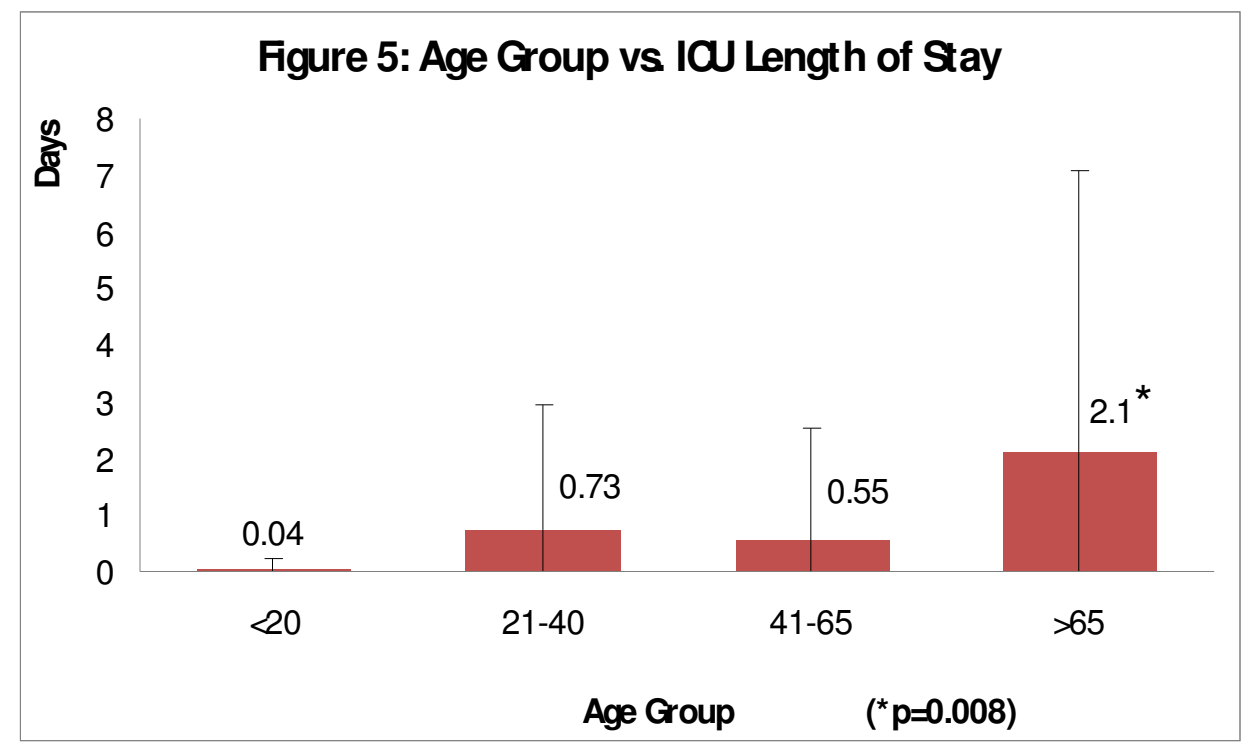

Figure 5: ICU Length of Stay (LOS). A significant increase was shown in ICU length of stay as the injured patient age increased as shown in this figure. 


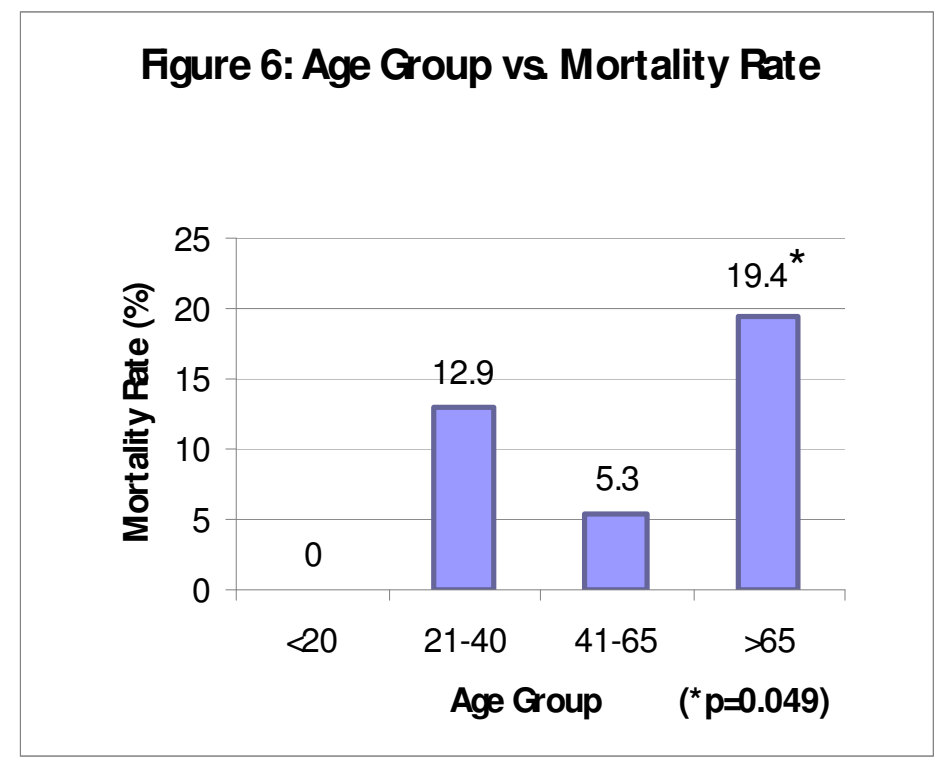

Figure 6: Age Group vs. Mortality Rate. Overall mortality rate were observed to increase significantly in pedestrians injured over at 65 . 


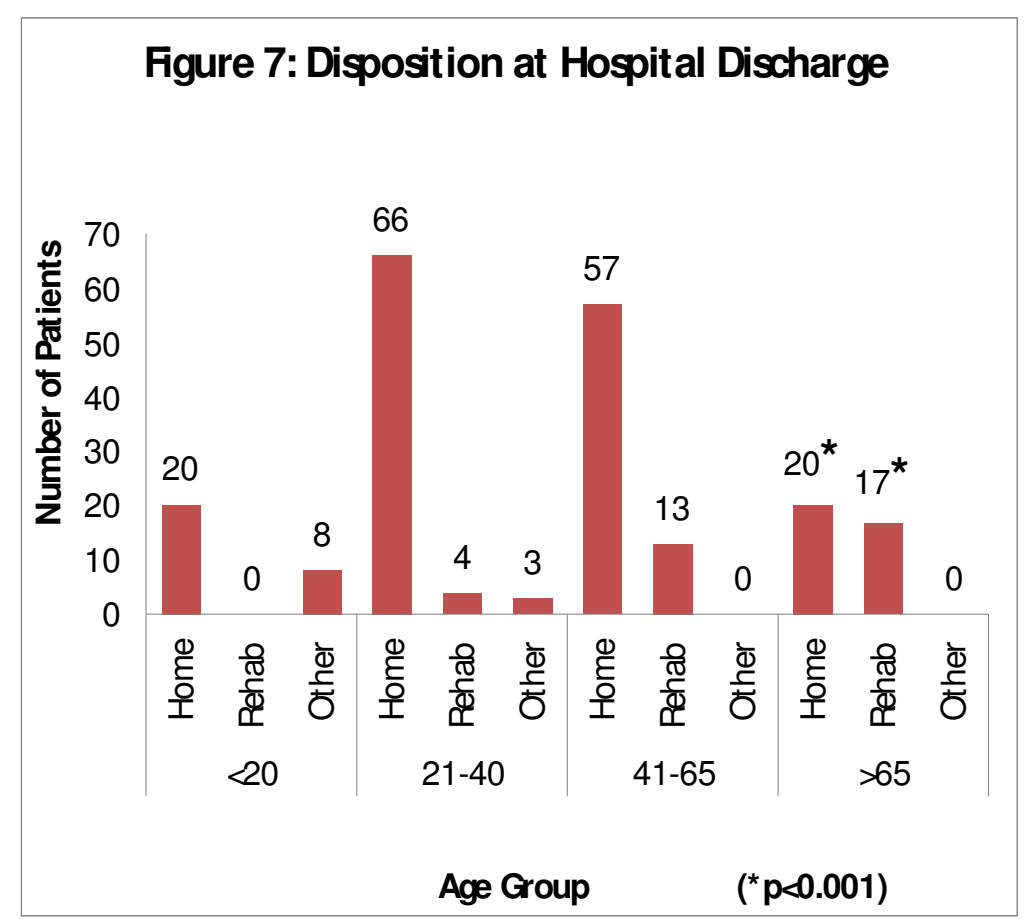

Figure 7: Disposition at Hospital Discharge. Rehab discharges increased as patient age increased as is shown in this figure. Other refers to release to authorities. 